\title{
Approaches to Development Research Communication
}

\author{
Tessa Lewin and Zachary Patterson
}

\begin{abstract}
This article traces the co-evolution between models of research communication and development. It looks at how creative and visual methods fit into this trajectory. It argues that the current growth in the accessibility of communication technologies has emerged alongside a strong revival of more linear, marketing-style understanding of development research communication, which threatens to undermine their progressive potential. It argues that despite development research communicators having many more options available to them, in terms of tools and approaches, and a much better understanding of how to integrate research and communication, they are also under increased pressure to prove impact, or show direct attribution. It argues that the more democratised communication becomes, the more difficult it is to do this.
\end{abstract}

\section{Introduction}

A few years ago a group of us in the Participation, Power and Social Change Team at IDS set up a reading group in an attempt to identify literature that resonated with the work we were doing that combined development research and communication. ${ }^{1}$ Many of us felt our approach to communication did not seem to be reflected in the literature that we were reading, specifically the highly instrumental debates on utilisation, uptake and impact. Much of the theoretical work that most closely reflected our own framings came not from the development sector, but from other fields cognitive linguistics, journalism, feminist literacy criticism, and critical theory. We also felt a strange discomfort between our excitement around new methods and tools, and our learned caution of magic bullets. We were in an environment where there was a strong, growing culture of communications as public relations, or corporate communication 'wrapped in participatory diffusion rhetoric', that was defining the field in a way we felt was antithetical to our own practice (Servaes 2008).

Unbeknownst to us at the time, we were in the midst of a rather dramatic change in UK government policy. Prior to 2010, the UK Department for International Development (DFID) was actively encouraging innovation in communication and a spend of 10-20 per cent of research budgets on communication (as well as a very broad understanding of what constitutes communication). In May 2010, however, this was reversed with a freeze on all marketing, advertising, and communications activity across the UK Government. ${ }^{2}$ The idea of the freeze is 'to maximise value for money and reduce or eliminate spend on anything that does not contribute towards or directly achieve research outcomes'. This environment makes people very nervous about doing any work that might be construed as non-value-for-money communication.

Concurrent to the freeze on development communication however, DFID are championing the Girl Hub - a project in which they are partnering with NIKE, a global clothing brand known for its marketing clout - to invest in the girl child as a route to alleviating global poverty. This seems to reflect either an inconsistency in their policies, or a strong endorsement of a particular neoliberal understanding of communications as marketing.

Insights from Hovland (2003) and Weiss (1977) can help in understanding the recent and ongoing changes in research communication. In 2003 Hovland noted that many of the current recommendations on communication aim to maximise the direct impact of research on policy 
and practice. In the process they frequently lose sight of the more gradual and indirect impact that research can have. The current focus is on instrumental change through immediate and identifiable change in policies, and less on conceptual change in the way we see the world and the concepts we use to understand it. The current literature therefore tends to encourage single loop learning (i.e. bringing about corrective action within existing guidelines), but largely overlooks the important but gradual contribution that research can make for double loop learning (i.e. independent and critical debate).

In 1977 Weiss wrote about the 'enlightenment function' of research - the process whereby research findings and new concepts 'percolate' and gradually filter through policy networks, thus indirectly influencing policy. Weiss argued that direct, instrumental change from research is rare, whereas indirect or conceptual change was relatively common, though much more difficult to prove or measure. Weiss' work suggests the importance of investing in non-instrumental approaches to development research communication. Much of the literature, and the field of development research communication, is divided into those who focus on direct, instrumental, measurable policy impact, and those who are more concerned with broader systemic change. This 'split' is not a new one.

What follows in this article is an attempt to make sense of the co-evolution of the broad trends or paradigms in development with models of research communication. The current landscape of development research communication contains a confusing, contradictory, smorgasbord of theories and approaches often littered with inconsistencies and incoherence. While this article is structured broadly chronologically, it is important to note that, though they originated in particular periods, many aspects from the approaches discussed are still with us. We hope that looking at some of the ways in which development, development research, and communication have co-evolved will offer some insights into the current range of approaches available to both researchers and practitioners.

\section{Historical overview of development research communication}

The evolution of research communication, and how different practitioners and theorists have approached it as a field, is inseparable from the evolution of development itself, and the various frameworks and theories of change, underlying different initiatives.

Still today, the English language doesn't clearly differentiate information (one way) from communication (multiple ways), let alone communications (the technology) from communication (the human factor)...

(Gumucio-Dagron 2008).

McPhail (2009: 3) defines development communication as

the process of intervening in one's day-to-day in a systematic or strategic manner with either media (print, radio, telephony, video and the internet), or education (training, literacy, schooling) for the purpose of positive social change. The change could be economic, personal, as in spiritual, social, cultural, or political.

What is regarded as 'positive' change is highly contingent on one's broader political view. McPhail (ibid.) points out that US foreign policy during the Cold War can be summed up in the two words 'stop communism'. The type, style, process, and content of research communication depends a lot on who both the audience and the political actors are thought to be. Development researchers are often thought of as handing over their work to political actors who then utilise it in informing policy decisions, but Wheeler (2007) emphasises there are new ways in which researchers themselves are seeing themselves as political actors, communicators, and facilitators. Some more recent research communication approaches have adopted more participatory and inclusive practices, utilising technology such as social media, street theatre and digital storytelling (Fisher and Kunaratnam 2007).

\section{Modernisation theory}

Development communication emerged in the 1950 s and 1960s to promote and support the modernisation programmes ushered in by Bretton Woods agreements, and clearly laid out in Rostow's five stages of modernisation (Rist 2002). They aimed at bringing the 'third world' up to speed with Western democracies.

Development communication was largely a technical function for the transfer of technology 
and promoting Western ideals of development. A number of communication models contributed to the idea of direct transfer - for example, the 'communications effects' model based upon the idea of sending 'magic bullets' of information from sender to receiver to impact behaviour, the use of mass media as a vehicle for transmitting the values of modernisation. Everett Rogers, Daniel Lerner, Lucien Pye and Wilbur Schramm all made significant contributions to the field at this time, stressing the important role that communication had to play in ushering in economic and political progress.

It is worth noting though that as early as the 1950s there were also development communication initiatives in the global North. For example, the radio drama The Archers was designed to disseminate agricultural information to farmers to help increase productivity in the years after the Second World War. The emergence of 'edutainment', the strategic use of entertainment to convey education messages to prompt social change, is well documented by Singhal and Rogers (1999).

\section{Dependency theory}

Dependency theory grew out of a critique of modernisation theory. Dependency theorists (such as Frank 1969) argued that Western development ideas were based on exploitative relationships between 'centre' and 'peripheral' countries and the 'development' they advocated maintained skewed global power relations, benefiting those countries at the centre, at the expense of the peripheral countries.

Dependency theorists argued that the interests of 'underdeveloped countries' would be better served by reducing their connectedness to a global market, than becoming further entangled in it. We can see in the spirit of dependency theory the roots of participatory communication, that focus of local engagement, with a critical awareness of power structures. These ideas are found throughout Freire, Fals-Borda, and Boal's work. ${ }^{3}$ Downing (2001) has expanded on the ideas rooted in dependency theory, and suggests that local social and political issues, as well as issues of development, can be communicated through a wide range of alternative media and communications, from street theatre and murals to dance and song and, more common today, uses of technologies of radio, video, press, and the internet. These forms of alternative media disentangle a local public from their traditionally acknowledged position of 'audience' in the global communications power hierarchy, and can invite them to be more involved in the informing of and learning from research communication approaches (Downing 2001).

However, the creation of knowledge, and therefore development approaches, that lack social communication and inclusive dialogue reinforce structural relationships of power, which help to maintain the monopolies of centre global control (Gaventa and Cornwall 2008).

\section{Popular communication}

Globally, the 1970s saw a continued growth in the use of popular forms of communication to impart messages - for example, comics, posters, and simple adult education materials. These methods of communication - often linked with adult education and awareness-raising, although more accessible - were still produced by educators and communicators for participants. In other words they were still built on a top-down approach that assumed that development was an engineering problem that could be fixed by the right innovation.

Nora C. Quebral is credited with first coining the term 'Development Communication' in 1972. She defined it as

the art and science of human communication linked to a society's planned transformation from a state of poverty to one of dynamic socioeconomic growth that makes for greater equity and the larger unfolding of individual potential.

Escobar argues that another change that happened at this time, with the debates ushered in by post-structuralism, is that people started asking very different questions about development. Post-structuralists pointed to the importance of language and discourse in constructing reality, and to meaning and representation in shaping our experiences of that reality.

Poststructuralist theory offers an important momentum to a set of pressing questions that are not adequately dealt with by other theories, particularly the production of subjectivity and identity through discourses 
and practices, the analysis of apparatuses that systematically link power and knowledge, and the construction of collective identities by social movements (Escobar 2000: 166).

He argues that a field of 'critical development studies' has emerged from the encounter between post-structuralism and development studies.

\section{Participation}

The 1980s and 1990s saw a growing emphasis on communication being integrated into participatory methodologies such as Participatory Rural Appraisal (PRA), Participatory Learning and Action (PLA) and Participatory Action Research (PAR). This participatory communication recognises the importance of the politics around knowledge production and emerged as an alternative approach to linear forms of communication. Participatory communication is a concept and practice involving citizens co-creating and sharing knowledge, experiences, and desires in order to pursue agendas of their own choosing. The emphasis of participatory communication is often on the process of creation or engagement, rather than products emerging from the process.

As Gumucio-Dagron (2001) explained, researchers working in participatory communications in the 1980s and 1990s began to realise that much of the ideal development communication processes were occurring at grassroots levels, where knowledge and action was informed by local input and experiences. In his book Making Waves, Gumicio-Dagron (2001) highlights a collection of participatory communication case studies from a variety of global communities. These examples demonstrate that the beauty of participatory communication is its ability to adapt to different forms and formats according to specific local needs, and that no single development communications blueprint can impose itself over the varying views and cultural differences encountered in development work.

Freire's work has been hugely influential in participatory development and communication. His work on the theory of dialogical communication outlines the intersection between basic human communication and participatory methodologies. For Freire (1994), the sharing of information, knowledge, trust, and commitment in any development project can best occur through participatory decision-making processes. ${ }^{4}$ As Freire (cited in Servaes 1996: 75) suggested, this idea

calls for new attitudes for overcoming stereotyped thinking and to promote more understanding of diversity and plurality, with full respect of the dignity and equality of peoples living in different conditions and acting in different ways.

Therefore, development efforts should be anchored in a local community's capacity to discern what is best for themselves, and how best to achieve their own development goals. Participatory development communications during the 1980s and 1990s initially made way for this way of thinking to be put into practice in the field.

\section{Critiques of participation}

Despite the popularity and growth of participatory methods, linear communication still dominated in many development interventions. Equally, many interventions that claimed to be participatory were criticised for 'faking it'. Servaes (2008) and others have pointed out that while references to 'top-down' approaches have fallen out of grace in the discourse of the highly political development aid community, many statements and reports are now advocating 'bottom-up' approaches with references to 'participation', 'empowerment' and providing 'a voice for the voiceless'. Hardly anybody seems to be concerned about the implicit contradictions these forms of 'hybridity' pose at both theoretical and applied levels. Servaes (2008) argues that much 'participatory communication' is still corporate communications or public relations wrapped in the rhetoric of 'participatory communication'.

\section{Power analysis}

One of the recurring critiques of participatory approaches is that they fail to adequately account for structural power (Kothari and Cooke 2001). McLuhan's (1964) classic text was one of the first to explore the spectrum of communication approaches and technologies during the early years of these initiatives, significantly analysing the interplay between power and communication. Ekstrom et al.(2010) recently took this review further by expanding on the ideas of participatory 
media, and argued against obscuring participatory media with the rhetoric of newness and making assumptions that it is always radical and revolutionary. As Mansell (2002), Morozov (2010), and Selwyn (2004) point out, one should always be sceptical of the optimism that accompanies innovative research communication approaches and technologies due to the digital divides and potential authoritative controls that accompany the use of these technologies. The political economy of development communications should be considered when supporting and implementing communication forms and strategies.

\section{Another development}

Notwithstanding these criticisms, there is a large and growing body of empowerment-driven participatory communication work that is highly cognisant of the various problematics of power and positionality that exist in development work, and is committed to the co-creation and sharing of knowledge expressed using a variety of communication channels that citizens find appropriate and relevant to their lives.

Melkote (2000: 40) argues that we should abandon development and focus instead on empowerment, which 'offers a more useful role for communication'. This approach is in a similar spirit to that of Quarry and Ramirez (2009) who argue for a new development based on listening rather than telling, and on respecting local knowledge and agendas.

From the legacy of both post-structuralism and participatory methods is an approach to development communication that makes us critically examine development and the grounds on which this has been structured, and asserts the value of alternative experiences and forms of knowledge, as well as the importance of local, contextual knowledge (Escobar 2000; Castells 2009).

\section{Creative and visual methods}

Many creative and visual methods have been introduced to facilitate local engagement in research and communications. Some methodologies, like digital storytelling, are based on Freire's notion that developing a critical consciousness is an essential precursor to social change, and that creative processes can facilitate this, as well as building solidarity between people, and enhancing their creative and technical skills.
These creative methods of communication are being used in critical reflection, to create environments that allow people to temporarily suspend their self-monitoring and give access to different forms of knowledge, and to consciously populate the mediaspace with non-mainstream representations and arguments.

The growth in the use of visual methodologies such as participatory video, digital storytelling, and photo voice draw on the work of visual anthropologist Wendy Ewald (1996), amongst others, and the Storytelling Centre in Berkeley. ${ }^{5}$ Furthermore, Rose (2007), Mitchell (2011), Prosser and Loxley (2008), and Spencer (2011) have all documented this work.

\section{New realities}

New global changes in demographics, in technologies, through the explosion of social networking and the multitude of ways people are accessing and engaging with information, and in the converging of 'old' and 'new' ways of operating in the field of development research communication, suggest that other significant trends are now emerging.

Jenkins (2008) shows that developments in communication technologies do not usher in a sea change in the communication landscape, but rather a gradual, chequered process, where the old begins to converge with the new, while continuing alongside the new.

The diffusion of 'the internet, mobile communication, digital media and a variety of social software tools throughout the world has transformed global news media and communication systems into interactive horizontal networks' that connect local and global individuals and issues (Haider 2011: 1). These circumstances have had direct impact on development research communication, allowing for unprecedented availability and distribution of knowledge and inclusive learning (Coleman and Blumler 2009; Ford and Gil 2001).

As accessibility and reach of research transforms, so too does the role and the definition of a 'researcher'. As noted above, researchers are more often finding themselves in situations where they are doing more than collecting and sharing knowledge. Today, many researchers are playing an active role in working with individuals 
who are directly impacted by research findings and development approach suggestions and policies. This change in role calls into question the traditional definition of 'researcher', but so does the transforming nature of producing and publishing information using alternative digital media and communications. With this development the once stark line dividing academia and professional and amateur writers (i.e. op-ed writers, bloggers, etc.) has become blurred.

On many levels the two broad approaches to development research communication introduced alongside the modernisation and dependency schools are still highly visible today - but the field is far more layered and complex, and there are many more available methods and tools, and many more exciting potential opportunities for development research communication practitioners to contribute to social change.

Sadly, the growth in the accessibility of communication technologies has emerged alongside a strong revival of neoliberal thought

\section{Notes}

1 We would like to thank Jethro Pettit, Joanna Wheeler, Alison Dunn, Nick Benequista, Laura Cornish, Jane Stevens, Peter Clarke and Elise Wach for their part in shaping this.

2 From DIFD correspondence 'Guidance on the Government's Marketing, Advertising and

\section{References}

Boal, A. (1995) Rainbow of Desire, London: Routledge

Castells, M. (2009) Communication Power, Oxford: Oxford University Press

Coleman, S. and Blumler, J.G. (2009) The Internet and Democratic Citizenship: Theory, Practice, and Policy, Cambridge: Cambridge University Press

Downing, J. (2001) 'Popular Culture, Audiences, and Radical Media', in J. Downing, Radical Media: Rebellious Communication and Social Movements, London, New Delhi and Thousand Oaks CA: Sage

Ekstrom, Anders; Jülich, Solveig; Lundgren, Frans and Wisselgren, Per (eds) (2010) 'Participatory Media in Historical Perspective: An Introduction', in A. Ekstrom et al., History of Participatory Media: Politics and Publics, 1700-2000, London: Routledge

Escobar, A. (2000) 'Place, Power, and Networks in Globalisation and Postdevelopment', in Gwim and influence in mainstream development. This brings with it a marketing-style communication model, which harks back to a much older, more linear, understanding of development research communication, albeit one that is now far more sophisticated and multi-sited. It seems ironic that in an era where we have so many more options in terms of tools and approaches, and a much better understanding of how to integrate research and communication, funders are demanding an approach based on calls to prove impact, or show direct attribution. Added to this is the complication that the impact of more inclusive, iterative, participatory models that have become increasingly possible as communication becomes more democratised, are notoriously hard to measure. It is precisely because these efforts are often built on, and integrated into, existing local networks and initiatives that it is harder to trace definitive influence. The more inclusive and participatory research communication becomes, the more that honest evaluation will show a contribution to social change, not attempt to claim attribution for it.

Communications Freeze for Research Programmes'.

3 See Freire (1970) and Fals-Borda (1987); see also Boal (1995).

4 See also, Servaes et al. (1996).

5 See www.storycenter.org (accessed 29 June 2012).

Wilkins, K. (ed.), Redeveloping Communication for Social Change, Maryland: Rowman and Littlefield Publishers, Inc.

Ewald, W. (1996) I Dreamed I Had a Girl in My Pocket: The Story of an Indian Village, with stories and photographs by the children of Vichya, India, New York: Doubletake Books

Fals-Borda, O. (1987) 'The Application of Participatory Action-Research in Latin America', International Sociology 2.4: 329-47

Fisher, C. and Kunaratnam, Y. (2007) Between Ourselves: The New Generation of Information and Knowledge Intermediaries, report from the 'Intermediary Workshop: Summarisers, Signposters, and Synthesisers', IDS, May 2007

Ford, T.V. and Gil, G. (2001) 'Radical Internet Use', in J. Downing, Radical Media: Rebellious Communications and Social Movements, London, New Delhi and Thousand Oaks CA: Sage

Frank, A.G. (1969) Latin America: Underdevelopment or Revolution?, New York: Yale University Press 
Freire, P. (1994) Pedagogy of Hope, New York: Continuum

Freire, P. (1970) Pedagogy of the Oppressed, New York: Continuum

Gaventa, J. and Cornwall, A. (2008) 'Power and Knowledge', in P. Reason and H. Bradbury (eds), The Sage Handbook of Action Research: Participative Inquiry and Practice, London, New Delhi and Thousand Oaks CA: Sage

Gumucio-Dagron, A. (2008) 'Vertical Minds versus Horizontal Cultures: An Overview of Participatory Process and Experiences', in J. Servaes (ed.), Communication for Development and Social Change, 2nd edn, London, New Delhi and Thousand Oaks CA: Sage

Gumucio-Dagron, A. (2001) Making Waves: Stories of Participatory Communication for Social Change, New York: The Rockefeller Foundation

Haider, H. (2011) Helpdesk Research Report: Social Media and Reform Networks, Protests, Social Movements and Coalitions, GSDRG Research Report, Birmingham: Governance and Social Development Resource Centre

Hovland, I. (2003) Communication of Research for Poverty Reduction: A Literature Review, ODI Working Paper 227, London: Overseas Development Institute

Jenkins, H. (2008) Convergence Culture: Where Old and New Media Collide, New York: New York University Press

Kothari, U. and Cooke, B. (2001) Participation: The New Tyranny, London and New York: Zed Books

Mansell, R. (2002) 'From Digital Divides to Digital Entitlements in Knowledge Societies', Current Sociology 50.3: 407-26

McLuhan, M. (1964) Understanding Media: The Extension of Man, New York: McGraw Hill

McPhail, T. (2009) Development Communications: Reframing the Role of the Media, Chichester UK and Malden MA: Wiley-Blackwell Publishing

Melkote, S. (2000) 'Reinventing Development Support Communication to Account for Power and Control in Development', in K. Gwim Wilkins (ed.), Redeveloping Communication for Social Change, Maryland: Rowman and Littlefield Publishers, Inc.

Mitchell, C. (2011) Doing Visual Research, London, New Delhi and Thousand Oaks CA: Sage
Morozov, E. (2010) The Net Delusion: The Dark Side of Internet Freedom, New York: Public Affairs, Inc.

Prosser, J. and Loxley, A. (2008) Introducing Visual Methods, Discussion Paper, London: Economic and Social Research Council National Centre for Research Methods

Quarry, W. and Ramirez, R. (2009)

'Communicating for Development: Setting the Scene', in W. Quarry and R. Ramirez, Communication for Another Development: Listening Before Telling, London and New York: Zed Books

Quebral, N. (1975) 'Development Communication: Where Does it Stand Today', Media Asia 2.4

Quebral, Nora (1972) 'What Do We Mean by "Development Communication", International Development Review 15.2: 25-8

Rist, G. (2002) The History of Development: From Western Origins to Global Faith, London and New York: Zed Books

Rose, G. (2007) Visual Methodologies, London, New Delhi and Thousand Oaks CA: Sage

Selwyn, N. (2004) 'Reconsidering Political and Popular Understandings of the Digital Divide', New Media and Society 6.3: 341-62

Servaes, J. (2008) 'Confusion about MDGs and Participatory Diffusion', Communication for Development and Social Change 2.3

Servaes, J. (1996) 'Participatory Communication (Research) from a Freirean Perspective', African Media Review 10.1: 73-91

Servaes, Jan; Jacobson, Thomas and White, Shirley A. (1996) Participatory Communication for Social Change, London, New Delhi, Thousand Oaks CA.: Sage

Singhal, A. and Rogers, E. (1999) EntertainmentEducation: A Communication Strategy for Social Change, Mahwah NJ: Lawrence Erlbaum Associates

Spencer, S. (2011) Visual Research Methods in the Social Sciences, London: Routledge

Weiss, C. (1977) 'Research for Policy's Sake: The Enlightenment Function of Social Research', Policy Analysis 3.4: 45-51

Wheeler, J. (2007) Creating Space for Engagement; Understand Research and Social Change, Citizenship DRC, Brighton: IDS 